Editorial / Editöryal

\title{
Keep improving with the same enthusiasm
}

\author{
Aynı heyecanla gelişmeye devam
}

\author{
Soner Sanioğlu $($ )
}

Department of Cardiovascular Surgery, Istanbul Mehmet Akif Ersoy Thoracic and Cardiovascular Surgery Training and Research Hospital, Istanbul, Turkey

In recent years, the Turkish Journal of Thoracic and Cardiovascular Surgery (JTCVS) has improved its international visibility and content quality. According to the 2021 journal citation report of Web of Science, the impact factor of the journal has increased by 75 percent compared to the previous year. As the Editor-in-Chief, I would like to congratulate previous Editorial Boards for this achievement, and I would like to express my thanks to the authors and reviewers for their valuable contribution and collaboration. As the new Editorial Board, our primary goal is to improve this increment rate.

The new Editorial Board consists of associate editors who have been working with devotion for a long time, and of experienced colleagues who have made significant contributions to our journal as reviewers. Our managing editors are Serkan Ertugay, MD in the Cardiovascular Section and Ekber Şahin, MD in the Thoracic Section. In addition, we will introduce a new topic from a "Biostatistician's Eyes," and we will work with Meral Yay, $\mathrm{PhD}$ for this section. We aim our readers to learn more about statistical methods and the interpretation of study results. Visual or graphical abstracts will be another novelty that we plan to adopt in our journal. These abstracts will be concise and pictorial and summarize the main findings of the paper allowing readers to understand the take-home message quickly. We believe that the visual abstracts will increase the interaction in social media and improve the citations.

The partnership with Publons, which was established in 2020, offers an advantage to reach wider reviewer network and evaluate their activities. This partnership also provides official recognition of the reviews for the JTCVS. I would like to thank Adem Ilkay Diken, MD and Serkan Ertugay, MD for their immense contributions for the establishment of the partnership. I believe that the benefits of Publons will be more evident in the new term.

The Cardiovascular Surgery and Interventions, our sister journal, continues to be published successfully. It has been already indexed in 14 international and national databases. The ULAKBİM application has been completed, and we expect it to be indexed at ULAKBIM very soon. I also would like to thank Bilgin Emrecan, MD and the Editorial Board for their significant efforts. The Cardiovascular Perfusion and Nursing, the third journal of our society, will be our Editorial Boards' next focus aiming to publish it regularly and get it indexed.

Şahin Şenay, MD has completed his term of Editorin-Chief for two years. I would like to thank him for his tremendous contributions to improve the future perspective of the JTCVS. I also would like to thank the other Editorial Board members whose terms ended for their significant input. Lastly, I would like to commemorate Dear İlker Mataracı, MD who was a talented surgeon and a good friend of mine. May he rest in peace.

The JTCVS has been in a committed improvement with valuable support of the previous Editor-in-Chiefs and Editorial Board members. The new Editorial Board will work devotedly, with the outstanding contributions of authors and reviewers, to improve the scientific quality of our journal. We look forward to receiving your submissions as researchers and contributions as reviewers.

Sincerely,

Editor-in-Chief

Received: October 05, 2021 Accepted: October 05, 2021 Published online: October 20, 2021

Correspondence: Soner Sanioğlu, MD. SBÜ Istanbul Mehmet Akif Ersoy Göğüs Kalp ve Damar Cerrahisi Eğitim ve Araştırma Hastanesi Kalp ve Damar Cerrahisi Kliniği, 34303 Küçükçekmece, İstanbul, Türkiye. Tel: +90 212 - 6922000 e-mail: sanioglu@gmail.com 